\title{
Más sobre El regreso (1975), de Francisco Rovira-Beleta: versión filmada del cuento "La resucitada" (1908), de Emilia Pardo Bazán ${ }^{1}$
}

\author{
José Manuel González Herrán \\ (UNIVERSIDADE DE SANTIAGO DE COMPOSTELA) \\ josemanuel.gonzalez.herran@usc.es
}

(recibido setembro/2017, revisado outubro/2017)

RESUMEN: Continuando y ampliando mi nota "Otro cuento de Emilia Pardo Bazán en la pantalla..." (La Tribuna, 9 [2012-2013]), este artículo ofrece una minuciosa descripción de todo lo que aparece en la pantalla (imágenes, diálogos, voz en off, música, efectos sonoros...) del mediometraje para televisión "El regreso", dirigido por Francisco Rovira-Beleta, para la serie de TVE "Cuentos y leyendas", estrenado el 28 de noviembre de 1975.

PALABRAS CLAVE: Emilia Pardo Bazán, cuento, "La resucitada", televisión, Francisco RoviraBeleta, "El regreso".

ABSTRACT: Continuing and expanding my note "Otro cuento de Emilia Pardo Bazán en la pantalla..." (La Tribuna, 9 [2012-2013]), this article offers a detailed description of everything that appears on the screen (images, dialogues, voice in off, music, sound effects ...) of the medium-length film "El regreso", a television version of the story "La resucitada", directed by Francisco Rovira-Beleta for the TVE series "Cuentos y leyendas" and premiered on November 28 of 1975.

KEY WORDS: Emilia Pardo Bazán, short story, "La resucitada", television, Francisco RoviraBeleta, "El regreso".

En el número 9 de La Tribuna (2012-2013, pp. 235-240) firmé una nota titulada "Otro cuento de Emilia Pardo Bazán en la pantalla: El regreso (1975), de Rovira-Beleta, versión

\footnotetext{
${ }^{1}$ Este trabajo se inscribe en el Proyecto de Investigación Ediciones y estudios críticos sobre la obra literaria de Emilia Pardo Bazán (Referencia: FFI2016-80516-P), financiado por el Ministerio de Economía y Competitividad, que dirige en la Universidade de Santiago de Compostela la Dra. Cristina Patiño Eirín.
} 
para TVE de "La resucitada»", donde daba noticia ${ }^{2}$ de una lectura filmada de ese relato ${ }^{3}$, que TVE había estrenado el 28 de noviembre de 1975, a las 22:30, dentro de la serie Cuentos y Leyendas en su "Primer programa". Aunque aquel mediometraje (aproximadamente 55 minutos) ha vuelto a pasar por la pequeña pantalla al menos en cuatro ocasiones (1982, 1989, 1996, 1997), no es exagerado considerarlo como casi desconocido. No está entre los 23 programas de aquella serie que se pueden ver en la sección "A la carta", de la página web de $\mathrm{TVE}^{4}$; pero, como ya indiqué en aquella nota, puede consultarse en los Archivos de TVE, donde solo permiten su visionado ${ }^{5}$, aunque no su copia ni préstamo. Por ello, en mi visita a esos archivos el 21 de octubre de 2013 dediqué varias horas a ver la copia que allí se conserva (en video, formato Beta, de no muy buena calidad), tomando minuciosa nota de todo lo que aparece en la pantalla: imágenes, diálogos, voz en off, música, efectos sonoros...6

En mi nota de La Tribuna, 9 añadí a la noticia del hallazgo un sucinto comentario de aquella adaptación en sus líneas generales, y -lo que a los pardobazanistas más podía interesar- las "fidelidades" e "infidelidades" respecto al relato original"; prometiendo para un próximo número de esta revista "el detenido estudio y comparación entre el texto de doña Emilia y la lectura filmada por Rovira-Beleta". A la espera de poder cumplir tal promesa, adelanto aquí algunos de los materiales previos a ese estudio pendiente: de momento, una provisional "puesta en limpio" de las notas que tomé en aquella ocasión ${ }^{8}$ :

\footnotetext{
2 También casi simultaneamente, en mi comunicación "Emilia Pardo Bazán, en la pantalla", presentada en un Coloquio Internacional en la Université de Bourgogne (Dijon), 15-16 de noviembre de 2013, y recogida en el volumen Littérature et cinéma: Allers-retours. Culture hispanique contemporaine. Textes réunis et présentés par B. Castanon-Akrami., F. Heitz, E. Le Vagueresse, C. Orsini-Saillet, Hispanistica XX, $\mathrm{n}^{\circ}$ 31. Dijon : Orbis Tertius-Université de Bourgogne, 2014, pp. 239-250.

3 "La resucitada", en Los Lunes de El Imparcial, 28 de junio de 1908, recogido en Cuentos trágicos, Madrid: Renacimiento, s. a. [1912], pp. 79-85; en Obras Completas, X (ed. D. Villanueva y J. M. González Herrán), Madrid: Fundación J. A. de Castro, 2005, pp. 445-448.

4 http://www.rtve.es/alacarta/videos/cuentos-y-leyendas.

${ }^{5}$ Empleo ese término en el sentido que da a visionar el Diccionario de la Real Academia Española (http://dle.rae.es/?w=diccionario): 'Examinar técnica o críticamente, en una sesión de trabajo, un producto cinematográfico, televisivo, etc.'

${ }^{6}$ Por supuesto, tampoco se ha editado el guión de aquel programa, firmado por el propio RoviraBeleta y José Manuel Martín ni me consta que se conserve; salvo -acaso- los herederos de sus autores, a quienes no he consultado.

${ }^{7}$ Del que me he ocupado en mi artículo "Realidad e irrealidad en los cuentos fantásticos de Emilia Pardo Bazán: «La resucitada» (1908)”, en D. Thion Soriano-Mollá, N. François et J. Albrespit (eds.), Fabrique de verité(s), vol. 2: L'œuvre littéraire au miroir de la verité, Paris: L’Harmattan, 2016, pp. 171-180.

${ }^{8}$ Sin llegar a hacer aquí un découpage del film (en el sentido de 'transcripción escrita de todo lo que muestra la pantalla', como los que ofrece la revista L'Avant-Scène Cinéma), lo divido en secuencias, describiendo o parafraseando el contenido de cadas una de ellas e indicando [entre paréntesis cuadrados] el minuto aproximado en que se inicia.
} 


\section{DESCRIPCIÓN DE EL REGRESO (1975), DE FRANCISCO ROVIRA-} BELETA

1. [01:00]

Por un camino entre árboles camina un sacerdote revestido con ropas litúrgicas (para oficio de difuntos), precedido de tres monaguillos, con cruz alzada, incensario e hisopo; se dirigen hacia un caserón o modesto palacio (aunque tanto el narrador como los diálogos se referirán a él como "castillo"), en cuya puerta abierta les espera un criado con librea.

2 [01:50]

En el interior del palacio; suben por unas escaleras y se dirigen a una estancia en la que hay varias personas rodeando el lecho en el que está tendida, inmóvil y con los ojos muy abiertos, una mujer; de rodillas a su lado, un hombre solloza, le besa las manos y musita " No puede ser, no puede ser...!". Una criada vieja abraza a dos niños gemelos que lloran. El caballero le cierra los ojos a la mujer, pero tras unos segundos, los ojos se abren y parecen mirar fijamente [02:20], mientras empieza a sonar la "Pavana para una infanta difunta", de Ravel (en versión para piano), y van pasando los primeros títulos de crédito:

RVE presenta El regreso, basado en un cuento de Emilia Pardo Bazán.- guión. J. Manuel Martín y F. Rovira-Beleta.- Dirección: Rovira-Beleta.

3 [02:50]

En una sala del interior del palacio, aquella dama borda ante un bastidor y habla con la vieja criada (a quien luego le llaman aya) sobre el sentido de ese bordar y sus esperanzas de boda; la vieja aya le recuerda que también la madre de la muchacha bordaba y, apenas concluido su bordado, le pidieron en matrimonio La conversación es interrumpida por unas voces que se refieren a alguien a quien traen: "es un herido y parece forastero... acaso herido en un accidente de caza..."

4 [03:40]

Unos criados traen a un hombre (el mismo que habíamos visto acariciando las manos de la difunta en las secuencias iniciales) herido sobre unas parihuelas. "No es de por aquí", dice uno de los criados; "tiene desgarraduras por todo el cuerpo... me barrunto que pudo ser un jabalí". La dama ordena que le lleven a una de las habitaciones.

$5 \quad[04: 20]$

Mientras la dama le limpia las heridas; el caballero recobra el conocimiento y ve primero borrosamente, luego con claridad- el hermoso rostro que le sonríe...

$6 \quad[04: 52]$

Voz del narrador en off: "Con la llegada del caballero todo cambió en el castillo de los Condes de Guevara..." Las atenciones de la dama despiertan en el caballero primero gratitud y luego amor. 


\section{$7 \quad[05: 40]$}

La dama y el caballero, convaleciente, juegan al ajedrez: ella gana repetidamente ("jaque... mate..."). Siguen escenas de juegos, columpios, abrazos, revolcones en el césped, besos... Voz del narrador: "Se juraron amor eterno, y un día las campanas de la capilla anunciaron la próxima boda".

8 [07: 06]

Un obispo casa a la pareja; él va vestido con uniforme militar.

9 [07:27]

La Condesa, en su cama, recibe en sus brazos un bebé que le trae una doncella por uno de los lados de la cama; inmediatamente, por el lado contrario, otra doncella trae otro bebé, gemelo del anterior. La madre los recibe y abraza, feliz y sonriente.

$10[07: 47]$

Mientras recita el narrador ("pasó el tiempo y el palacio se llenó de balbuceos infantiles... Los niños crecían y aumentaba la dicha en el corazón de los Condes..."), vemos a los dos gemelos que se reúnen con su viejo preceptor: "Hoy daremos la clase paseando por el bosque". Mientras se alejan, el marido comenta cómo serán cuando crezcan y ella, con gesto sombrío comenta: "Me gustaría que siempre fuesen así, que no creciesen nunca... Me asusta el paso del tiempo..."

11 [08:30]

Un grupo de ciervos es observado por los niños y su madre, montados a caballo.

12 [09: 30]

Los niños se suben a sus poneys y reanudan el paseo con su madre. Uno de ellos, que se ha quedado rezagado, hace correr a su poney, y el niño pide auxilio a su mamá; el caballo de esta galopa hasta alcanzar al niño y cuando ya está junto a él, la madre cae del caballo y se golpea la cabeza con un tronco.

13 [10:14]

La Condesa, inmóvil e inconsciente, no parece oír las llamadas de sus hijos: uno de ellos se queda a su lado y encarga a su hermano que vaya a pedir ayuda al castillo. La madre sigue inmóvil, pero con los ojos bien abiertos.

14 [10:41]

La Condesa reposa en el lecho, siempre inmóvil y con los ojos abiertos; los médicos explican al Conde que han hecho todo lo posible; pero, "sin duda, el golpe de la caída ha paralizado su cerebro; lleva tres días inconsciente y solo un milagro podrá salvarla..."

15 [10:41]

Volvemos a ver las secuencias iniciales: la cruz, los monaguillos, la entrada en el castillo, las personas en torno a la dama muerta, el caballero que le cierra los ojos (y estos se abren), el cura que administra los óleos a la muerta... 
16 [13:15]

Dos criadas están lavando el cuerpo de la Condesa, y peinándola, mientras comentan que está más hermosa que nunca: "Parece una estatua de alabastro...", dicen.

17 [13:46]

La Condesa, vestida con el blanco hábito de la Merced, y colocada sobre un féretro abierto, es llevada a hombros de unos criados, seguida por el esposo, los hijos, familiares y demás servidumbre, a una pequeña iglesia o ermita campestre.

18 [14:15]

En el interior de la iglesia, mientras suena (ahora en versión orquestal) la "Pavana..." de Fauré, asistimos al funeral. Tras las preces y ritos del cura, unos criados colocan sobre el féretro una tapa de cristal transparente $y$, a hombros, atravesando oscuros corredores subterráneos, bajan a la cripta, donde queda depositado. Todos abandonan la iglesia, se cierra la verja y la Condesa queda en su féretro, con los ojos bien abiertos. Voz del narrador: "Y la dejaron sola... y desde aquel día la tristeza y la melancolía se apoderaron del castillo".

19 [17:03]

Al tiempo que la voz del narrador lo va explicando, vemos que el Conde pasa las noches en vela, en su despacho, y le sorprende el alba dormido sobre su mesa.

20 [17:09]

Narrador: "Y hasta los niños dejaron de jugar y se volvieron taciturnos". Ambos en su habitación, muy tristes, comentan que si el caballo no se hubiese desbocado, la madre no habría muerto.

21 [17:29]

Entra el preceptor, que les anuncia que hoy reanudarán las clases; pero los niños no quieren. "Está bien -responde; hablaré con vuestro padre".

$22[17: 42]$

Conversación entre el preceptor y el Conde; como los niños están muy tristes por la muerte de la madre, hay que hacer algo: sobreponerse al dolor. "Los muertos no regresan, no podemos rescatarlos". El consejo del preceptor va más allá: hay que borrar cualquier presencia de la dama muerta, tanto para los niños como para todos los de la casa.

23 [18:20]

En efecto, vemos cómo las criadas cubren con un paño el retrato de la Condesa, recogen sus ropas y sus joyas...

24 [18:47]

Los niños, dirigidos por una doncella, rezan al pie de la cama, antes de acostarse, pidiendo por su madre que está en el cielo. 
25 [19:10]

Cuando los niños ya están acostados, entra el padre y les anuncia que a partir de mañana, todos los días irán de paseo a caballo; uno de los gemelos dice que ya no quiere volver a montar a caballo, pues lo considera culpable de que muriese su madre. Pero el padre le argumenta que ella sufrirá en el cielo si ve que su hijo está enfadado con su caballo. Les nuestra una estrella muy brillante, desde donde su madre les está mirando, "como en un espejo".

26 [20:13]

Los niños juegan, acompañados de su preceptor, tirando al arco sobre una diana. Un criado trae los dos poneys y los niños emprenden un paseo a caballo.

\section{7 [20:13]}

Tormenta en el cielo nocturno; rayos y truenos. Vemos a la Condesa en la cripta, encerrada en el féretro, con sus ojos abiertos e inmóviles. Un murciélago revolotea, su sombra cruza y se proyecta en el rostro de la dama, que empieza a parpadear insistentemente. Mira hacia los lados, ve la bóveda de la iglesia y entiende dónde está. Extiende sus manos, que tropiezan con la tapa del féretro; se da cuenta de que tiene sobre el pecho un gran crucifijo de metal y con él empieza golpear la tapa de la urna, cuyos cristales se rompen (alguno de ellos parece que le hiere en el rostro). Al fin, consigue salir del féretro, salta al suelo y, tras dar gracias a Dios, llorando, sale de la cripta. Camina por los pasadizos, iluminada por los rayos, y sale al exterior, donde Ilueve copiosamente. Sigue caminando, con una alegre sonrisa bajo la Iluvia.

28 [23.39]

La dama golpea enérgicamente el aldabón del castillo: “AAbrid, abrid la puerta!”. A la respuesta del criado ("¿quién Ilama? no son horas de turbar la paz de esta casa"), la dama se identifica: "Soy vuestra señora, la Condesa"

29 [24:22]

Acude otra criada, que pregunta quién Ilama; el criado responde que es un alma en pena, un espíritu que dice ser la Condesa, y que parece su voz...

30 [24:34]

Al fin, los criados abren, y al verla, reaccionan aterrorizados: “ $i$ Tan horrible me encuentras, que no te alegras de mi vuelta?", pregunta ella al criado principal. Este va hacia el interior de la casa, anunciando: "El espíritu de la señora ha resucitado... el ama ha resucitado... ha vuelto de su tumba..."

31 [25:00]

El Conde sale de su habitación, abrochándose la bata. La Condesa camina por el pasillo, vestida con su hábito y los criados la miran pasar asustados. Cuando el esposo la ve y expresa asombro, la dama (que le Ilama Javier) explica. "Soy yo, tu esposa, que vuelvo para no separarme de tu lado..." La Condesa se despoja de la toca y se ofrece 
al caballero, que reacciona de manera pasiva: la abraza, pero su rostro no expresa alegría, sino asombro y extrañeza. Pide a los criados que se acerquen, sin temor, porque la señora ha vuelto; les ordena que den la noticia y anuncien la fiesta con que se celebrará. Únicamente la vieja aya se acerca y abraza a la resucitada.

32 [26:40]

Mientras la Condesa se dirige al cuarto de los niños, el Conde ordena que preparen la alcoba de la señora.

33 [27:00]

La Condesa se acerca a la cama de uno de sus hijos, que está dormido, le abraza y le besa, mientras el niño parece agitado en una pesadilla; cuando abre los ojos y ve a la dama reacciona aterrorizado. Ante las palabras de quien se declara como su madre, replica: “¡No, mi madre está en el cielo! ¡váyase de aquí...!” También el otro gemelo reacciona incrédulo: “Es una bruja!". El padre entra y aconseja a la dama que se retire: "Yo cuidaré de ellos". Ella así lo hace, acompañada de la vieja aya.

34 [28:05]

La vieja aya da orden a las doncellas que todo vuelva a estar como antes, para que la Condesa no se percate de nada. Una doncella quita el paño blanco que cubría el retrato. La otra doncella le comenta: “ ¿No te produce escalofrío tocar las cosas que ha tocado ella?"

35 [28:26]

Una fiesta y comida en los jardines del palacio: no hay muchos comensales. Un cuerpo de baile ejecuta una danza, vagamente goyesca. Unos criados traen un gran pastel, que colocan delante de la pareja anfitriona. La Condesa corta trozos y empiezan a repartirse, mientras el esposo explica que el pastel lo ha hecho ella misma con sus manos: inmediatamente, los invitados hacen gestos de extrañeza o repugnancia y nadie osa tocar el pastel. El propio esposo se lleva un trozo a la boca, pero no puede comerlo: ante el reproche de la dama se excusa (y también a los demás invitados, que tampoco prueban el pastel), porque la comida ha sido muy abundante. Pero ella intuye la razón y le dice: "Observa sus caras, ninguno me mira a los ojos..." Decide marcharse, pidiendo a su marido que invente una excusa. Él también abandona la mesa, mientras algunos invitados -el médico entre ellos- comentan cuál habrá sido la causa de su vuelta a la vida. El médico ofrece la explicación científica: "Sin duda, sufrió un ataque de catalepsia" (y lo explica médicamente...) Ante la pregunta de si esa enfermedad deja alguna huella responde: "En el enfermo, ninguna; solo afecta a los que conviven con ella. Siento piedad por la Condesa de Guevara; y pienso que tal vez más le valiera haber muerto de verdad".

36 [32:29]

Tumbada sobre en su cama, la dama Ilora; no quiere que entre nadie: ni siquiera su esposo, que llama a la puerta. 
37 [32:57]

La dama sigue reclinada en su lecho, con la misma expresión, mientras una doncella abre las cortinas y le anuncia que el Conde y sus hijos la esperan para dar un paseo a caballo; la Condesa responde que no desea salir de sus habitaciones y que pueden prescindir de ella. Cuando la criada hace ademán de marcharse, le pregunta que por qué ya no le toma de las manos, como antaño, y por qué habla a distancia, con temor. "No es temor, replica ella, es respeto..." La Condesa comenta: "Desde que he vuelto soy una extraña de la que deseáis manteneos a distancia..." Explica que ya nada es como antes, y que incluso sus hijos escapan de su presencia... "Me estoy acostumbrando a la soledad".

38 [34:50]

Desde el balcón abierto, la Condesa ve cómo su esposo y los gemelos salen de paseo a caballo...

39 [35:16]

La Condesa ante el espejo, escruta su rostro. Aparece el preceptor, que acude citado por la señora. Esta le encarga que, pues tiene ascendiente sobre los niños, influya en ellos para que entiendan que no hay nada sobrenatural en lo sucedido, que todo fue un accidente, que ella no es una aparecida, ni un ser del otro mundo. Él explica que los niños tienen una sensibilidad poco común, y ello les impide aceptar su vuelta como algo natural. "Y si los mayores nos resistimos a creerlo, ¿qué van a hacer los niños...?" La conclusión de la dama no puede ser más desconsoladora: “¿Me queréis decir para qué he vuelto...?"

40 [37:07]

El padre y los niños pasean a caballo por el campo. Él les ordena que regresen, pues quiere seguir por su cuenta, y así lo hacen. El padre se detiene a beber en una fuente y parece meditar...

41 [37:30]

La Condesa le pregunta a un criado que está manipulando un pequeño armario en la pared; este explica que está colocando la llave de la cripta. Como está presente el aya, Dorotea le reprocha que ya no muestre hacia ella el afecto de antes, que le huye... Cuando la criada le explica que está reponiendo las cosas suyas que antes estaban escondidas porque el Conde había ordenado guardarlas, para no afectar a los niños, ella replica: "Y para que olvidaran a su madre..."

42 [38:47]

Los niños regresan a casa, montados en sus poneys; su madre se les acerca sonriente, pero los niños se marchan asustados y se refugian en el preceptor.

43 [39:46]

Desde el balcón, la Condesa ve cómo su esposo regresa de su paseo a caballo; enjuga sus lágrimas. Él está escribiendo en su despacho, cuando ella entra; le explica que ha 
regresado solo porque ha ido a inspeccionar cómo están los sembrados. Ella intenta entablar conversación, pero esta no es fluida. La Condesa le reprocha que todos le traten como a una extraña. Cuando el esposo responde que el médico la curará, la señora replica que no necesita al médico, sino el cariño de los suyos. Los niños la rechazan, los criados también, él busca cualquier pretexto para alejarse. Ella insiste en que está sana, que todo fue un accidente, "Cálmate; con el tiempo nos iremos acostumbrando". "¿Acostumbrando a qué?" Él sugiere que se tome un cordial, pero ella le reprocha que lo necesita es su cariño; “¿Por qué no me besas, por qué no duermes en nuestra alcoba? ¿Por qué me miras con esos ojos tan duros y tan distantes...? Voy a mi alcoba: allí estaré aguardándote; si es verdad que me quieres, no te retrases..."

44 [42:53]

En su habitación, ante el espejo del tocador, Dorotea lleva un camisón transparente y escotado; se perfuma detrás de las orejas y se tumba en su lecho. Vemos las piernas del caballero, que va caminando lentamente por los pasillos, hacia la habitación de su esposa. Ella le espera sonriente; pero, desde dentro de la alcoba, vemos cómo el pestillo se mueve, vacila y desiste: el caballero se ha marchado. Ella se cubre con una prenda, sale de su habitación y entra en la del esposo: “¿Por qué no has entrado? Mírame: llevo las mismas ropas del día en que nos bendijo el sacerdote; me he puesto el mismo perfume y vengo a ti con el mismo deseo... besa mis labios y verás que no están fríos..." Él la acaricia, la besa, pero se interrumpe: "No puedo... De donde tú has vuelto no se vuelve jamás". Ella cae llorando a sus pies.

45 [45:22]

La imagen de un gran Cristo crucificado, en primer plano, nos indica que estamos en ámbito sagrado; la Condesa acude al cura, a quien pide que le escuche en confesión... Comienza un murmullo, pero no entendemos qué se dice.

46 [46:00]

La Condesa abre un armario ropero, acaricia el uniforme militar de su esposo, y toma un manto con capucha. Sale al exterior y la vemos galopando por un camino entre árboles. Llega a una mísera casucha y llama a su puerta. Es la casa del herrero, a quien le encarga una Ilave como la que le muestra. Allí mismo e inmediatamente, el herrero cumple el encargo.

$47[47: 45]$

El caballo de la Condesa galopa en la noche por un camino a la orilla de una corriente de agua. Se detiene, la dama baja del caballo y arroja su capa a las aguas. Regresa a casa y coloca de nuevo la llave de la cripta en su pequeño armario.

48 [48:40]

La Condesa entra en la habitación donde duermen sus hijos y se despide de cada uno de ellos con un beso. Abre un arcón y saca el hábito de la Merced. Lo toma en sus manos y se cerca a la cámara hasta tapar su objetivo. 
49 [49:40]

La doncella abre las cortinas de la habitación de Dorotea y descubre la cama vacía. Acude corriendo en busca del señor y le anuncia que la señora ha desaparecido: no aparece en toda la casa. El Conde ordena a sus criados que se dividan en grupos y la busquen: el cura formula deseos para que aparezca sana y salva: "A decir verdad, creo que todos hemos contribuido a su marcha" El preceptor lo confirma: "Tal vez todos tengamos un poco de culpa". Pero el Conde replica: "Yo soy el único culpable".

50 [50:30]

Los criados con pértigas rastrean la corriente. Un criado trae el estribo y parte de la silla de montar. Otros criados sacan con sus pértigas el manto de la señora. Un criado deduce que el cuerpo aparecerá en el fondo de la laguna. Todos regresan al castillo.

51 [51:00]

Mientras se oye al narrador "Y la buscaron inútilmente... Unos pensaban que las alimañas habrían acabado con ella..., pero otros pensaron que su desaparición había sido un milagro, igual que su resurrección anterior..." Sigue contando (y la pantalla lo muestra) que un día el aya descubrió que del arcón habían desaparecido el sudario y el escapulario que Ilevaba puestos. Cuenta también que el santero de la capilla bajó a la cripta, que permanecía cerrada, y se encontró con que allí estaba el cuerpo de la Condesa, cuyo semblante estaba tan plácido que parecía sonreír... Así lo vernos; pero también que sus ojos están cerrados.

52 [51:43]

Narrador: "Así fue el final de la Condesa de Guevara, según cuenta una legendaria tradición..."

53 [51:51]

Sigue el Narrador: "Sin embargo, hay quienes aseguran que fue otro muy distinto el desenlace de la leyenda".

54 [51:57]

Haciendo un retroceso en los hechos, volvemos a ver la secuencia de la conversación de la Condesa con el capellán. A partir de aquí se repiten las secuencias de la confesión, de la doncella que encuentra vacía la cama, de la señora arrojando su manto al agua, su visita al herrero. Pero la voz en off explica que la dama fue a pedirle hospitalidad. Vemos de nuevo la secuencia de quienes buscan en la laguna, el hallazgo del estribo y de la capa...

55 [52:50]

El capellán, en el púlpito, predica sobre la desaparición de la Condesa. Acusa a quienes le oyen: "Vosotros la arrojasteis de nuestro lado con vuestra superstición y vuestro desamor". Continúa el narrador, explicando que día tras día, las preces de los moradores del palacio eran como un mudo clamor rogando a Dios para que pudieran 
hallar, sana y salva a la señora. Hasta que al fin consiguieron que esta, que continuaba en casa del herrero, dejara su refugio para regresar al castillo.

56 [53:35]

La señora sale de casa del herrero y regresa a la suya: los gemelos la ven llegar desde el balcón; las campanas de la capilla anuncian el regreso de la Condesa, recibida amorosamente por los suyos: vemos cómo sus hijos la abrazan, y luego el esposo, mientras el narrador concluye que "así renació una esperanza que sería ejemplo para las generaciones venideras..."

57 [54:21]

Créditos finales: Productor. Fotografía. Montaje. Laboratorio. Reparto, etc.

\section{El regreso (1975). Serie "Cuentos y Leyendas""}

Director-Realizador: Francisco Rovira-Beleta

Guión: Francisco Rovira-Beleta y José Manuel Martín, sobre un cuento de Emilia Pardo Bazán. Productor: Martín Cabañas, para TVE

Fotografía (en color): Juan Martín

Montaje: Magdalena Pulido.

Formato de filmación: celuloide $16 \mathrm{~mm}$.

Formato de grabación y archivo: Video Beta

Laboratorio: Fotofilm, Madrid.

Duración: según la ficha de RTVE: 59 minutos; la copia que he consultado sobrepasa en poco los 55 minutos.

Fecha de producción: $1970[\dot{i}]$

Estreno: TVE ( $1^{\text {a }}$ cadena), 28 de noviembre de 1975, a las 22:30.

Intérpretes: Elisa Ramírez [la Condesa], Máximo Valverde [el Conde], José Manuel Martín [preceptor], Ana del Arco [aya], Fernando Romero y Ricardo Cruz [los hijos], Paula Gardoqui, Roberto Cruz, Salomé Guerrero, Rafael Vaquero, José María del Val [criados, amigos de la familia, capellán, herrero...]

Resumen argumental [según la ficha de TVE]: “Todo comienza con la muerte de una joven condesa, que después de enterrada, y cuando todos tratan de acostumbrarse a la terrible idea, vuelve a la vida, pues lo que sufrió fue una muerte aparente por catalepsia".

\footnotetext{
${ }^{9}$ Reproduzco la ficha que cerraba mi artículo en La Tribuna, $\mathrm{n}^{\circ} 9$
} 